\title{
Volviendo a las raíces. Orígenes y consolidación de la Dirección y Gestión de Cuentas Publicitaria. El paso definitivo en la estructuración del modelo de agencia de publicidad moderna.
}

\author{
Isabel SolAnAS GARcíA \\ Universidad Ramón Llull \\ isabelsolanasgarcia@gmail.com
}

\begin{abstract}
Resumen:
Sobre el proceso de construcción de la industria publicitaria moderna. Síntesis evolutiva, desde una perspectiva histórica, de los orígenes y consolidación de la función profesional de Dirección y Gestión de Cuentas Publicitaria en las agencias de publicidad modernas.
\end{abstract}

Palabras clave: Dirección de Cuentas; Account Managment; Account Direction; full service agency; publicidad moderna; historia de la publicidad moderna.

\section{Back to the roots. Origins and consolidation of the Account Managment and Direction in advertising. The last step in the structuring process of the modern advertising agency model.}

\begin{abstract}
:
This article is about the construction process of the advertising industry in the early years especially interesting around the period between 1880 and 1920 in the USA). A summary historical view of the origins and consolidation of de Account Direction in Advertising in the modern advertising agency model. A look back at the roots of this advertising professional specialize.
\end{abstract}

Key Words: Account Direction; Account Management; modern advertisin; full service agency; modern advertising history.

\section{Referencia normalizada:}

Solanas García, I. A. (2014): Volviendo a las raíces. Orígenes y consolidación de la Dirección y Gestión de Cuentas Publicitaria. El paso definitivo en la estructuración del modelo de agencia de publicidad moderna. Historia y Comunicación Social. Vol. 19. Núm. Especial Febrero. Págs. 401-411.

Sumario: 1. Introducción. 2. Marco teórico, método y fuentes. 3. En busca de las raíces de la Dirección y Gestión de Cuentas: del agente de publicidad a la agencia de publicidad moderna. 4. La especialización y la integración de los servicios en la agencia de publicidad moderna. 5. El reconocimiento de la función Ejecutiva en la full service agency. 6. Conclusiones. 
La Dirección y Gestión de Cuentas, una de las áreas de especialización profesional publicitaria tradicional, tuvo su implantación y desarrollo más claros en el modelo de agencia conocido como full services agency. Las diversas fuentes estudiadas en torno a sus orígenes permiten afirmar que, a finales del siglo XIX, la figura del profesional de cuentas ya está presente en algunas agencias de publicidad aunque a veces se muestre un tanto difusa o dispersa en sus atribuciones. Sin embargo, entre 1900 y 1920 ya aparece claramente definida y su presencia consolidada en diversas agencias. Para la autora, la definición y el reconocimiento otorgado a esta nueva función profesional supuso la culminación del proceso de modernización de la actividad publicitaria y cerró el proceso de definición y construcción de un modelo de agencia paradigmático, la full service agency, que se irá perfeccionando a lo largo del siglo XX. Este trabajo trata de sintetizar los orígenes y evolución de esta especialización profesional. La indagación retrospectiva se focaliza en Estados Unidos, país donde despegó con mayor vistosidad la industria publicitaria y la agencia de publicidad moderna, protagonista e impulsora de la creación de esa industria.

The practitioner was working on and solving managerial problems before the academicians started writing about them. (Wrend, 1977: 13)

\section{Introducción}

En las dos últimas décadas del siglo XIX confluyeron una serie de circunstancias económicas, sociales y comerciales que, en su conjunto, configuraron un escenario favorable para el despegue definitivo de la actividad publicitaria moderna. Las transformaciones experimientadas en los procesos de producción y en las condiciones de vida de la sociedad se manifestaron con mayor claridad en esos años y trajeron consigo importantes novedades en las formas de consumo. Los procesos de urbanización, los avances en el transporte, los cambios demográficos acompañados de algunos grandes movimientos migratorios, las innovaciones de carácter técnico y científico trasladadas a la industria y, por supuesto, el avance de los medios y sistemas de comunicación en general y su incidencia en el desarrollo empresarial, son algunas circunstancias claves que explican esa transformación social y cómo ésta favoreció el paso de una actividad anunciadora desestructurada a la creación de un sistema publicitario moderno. En este contexto complejo, numerosos fabricantes, y también distribuidores, movidos por una nueva visión y por nuevas expectativas comerciales, vieron la necesidad de multiplicar sus esfuerzos para impulsar la comercialización y venta de sus productos. Muchos de ellos, intuyeron tempranamente el papel decisivo que podía tener la publicidad como medio principal para dar a conocer sus productos =y marcas= a grandes grupos de población, impulsando así su distribución a gran escala. Aconsejados por las agencias de publicidad, dieron una mayor relevancia a la publicidad y encontraron en ella la vía principal para dar a conocer sus productos y marcas, despertar el interés hacia ellos, fomentar su recuerdo y ganarse la confianza y aprecio por parte del público. La publicidad, en su dimensiones de comunicación 
informativa y persuasiva, se convirtió en una herramienta estratégica para la extensión e intensificación de las ventas y la distribución y para la implantación de las marcas.

Las primeras agencias de publicidad modernas, cuya aparición se manifiesta entre las décadas de 1860 y 1880, ejercieron una influencia decisiva en la extensión de esa nueva visión moderna de cómo debían conducirse los negocios. Fueron las precursoras de una filosofía de marketing en la que la comunicación comercial, y la publicidad en particular, adquirían un destacado protagonismo. Estas agencias modernas actuaban guiadas por unos principios de negocio distintos a los de sus predecesoras. La atención que aquellas parecían dedicar antaño, casi exclusivamente, a los medios -la prensa, fundamentalmente- se decantaba progresivamente hacia los anunciantes y éstos empezaban a convertirse en el eje central de su actividad. El deseo de dar respuesta profesional a las diversas necesidades de los anunciantes se convirtió en el criterio dominante que marcaría las decisiones y actividades de las agencias, transformando su appearance y su performance. Las relaciones profesionales entre anunciantes y agencias se estrecharon y éstas asumieron un servicio profesional general de consejo publicitario y de marketing. De este modo, las agencias de publicidad fueron revisando sus métodos de trabajo e incorporaron formalmente nuevos servicios y perfiles profesionales en sus estructuras. Hacia 1900, algunas agencias de publicidad ya desarrollaban planes de publicidad y campañas más o menos complejas y su estructura organizativa mostraba la existencia de departamentos, o áreas funcionales, con desempeños propios, en los que trabajaban distintos especialistas. La ampliación de funciones y departamentos trajo consigo una nueva sistematización organizativa que desencadenó la formalización definitiva del perfil profesional de cuentas. A principios del siglo XX esta figura profesional ya se reconoce y su presencia parece extendida. Originalmente, su aparición será el resultado de aglutinar en una especialización profesional las labores de carácter comercial, de captación y relación con los clientes, de asesoramiento sobre los medios y la actividad publicitaria en general, pero también la labor de orientación, conducción y gestión de los procesos de trabajo que requería la actividad anunciadora del cliente en su conjunto. Las responsabilidades de este perfil profesional fueron ampliándose a la vez que focalizándose y en él también se delegaron algunas funciones que, tradicionalmente, venían desempeñando, de forma directa y personal, los directivos de las agencias. De este modo, también se reglamentó una nueva metodología y rutina profesional que fue extendiéndose en las agencias. El moderno profesional de cuentas se convirtió en una especie de representante y suministrador del servicio global de la agencia, asumiendo un rol vertebrador -en sus ventientes de organizador y coordinador- de ese servicio. En 1920, en diversas agencias se constata la presencia de un staff ejecutivo que, con diferentes rangos y atribuciones, lidera la relación con los anunciantes. A nuestro juicio, esta fue la fase final con la que concluyó la construcción de un modelo de agencia paradigmático que se perfeccionará en las siguientes décadas del siglo XX pero, además, también representó la culminación del proceso de transformación y modernización de la actividad profesional publicitaria. 
Propósitos de este trabajo:

- Ofrecer una síntesis evolutiva de la aparición, definición y consolidación de la función profesional de cuentas.

- Mostrar argumentos y evidencias que soporten que la formalización profesional de esta función ejecutiva, o de cuentas, constituyó la fase final de construcción de un modelo de agencia de publicidad paradigmático.

- Mostrar la relevancia de este perfil profesional y su contribución histórica en el proceso de modernización de la actividad publicitaria .

\section{Marco teórico, método y fuentes.}

Este trabajo se ampara en la vertiente profesionalista del marco teórico publicitario sin olvidar el cuerpo teórico publicitario en general y su naturaleza interdisciplinar. Se recurre a la vertiente pragmática de la actividad publicitaria para abordar, en sus orígenes modernos, el estudio de los perfiles profesionales, las metodologías de trabajo de las agencias de publicidad, la organización del sistema publicitario en su conjunto y, en particular, la relación profesional entre agencias y anunciantes. Adicionalmente, se contemplan, a modo de marcos complementarios, los sistemas empresariales, del marketing y del management, actuando éstos como referentes generales en la observación del comportamiento de agencias y anunciantes como organizaciones empresariales. Por último, el trabajo presentado obedece, lógicamente, a una perspectiva histórica que centra su atención en Estados Unidos, aproximadamente, entre los años 1880 y 1920, tomando ese periodo como referente central, sin que ello actue de limitación para la necesaria observación de sucesos anteriores a ese periodo. La investigación se fundamenta en los métodos hipotético-deductivo y analítico-interpretativo. La selección de fuentes fiables, relevantes, de base histórica y especializada, constituye el punto de arranque para posteriormente proceder al análisis e interpretación de la documentación obtenida con la pretensión de reconstruir un fragmento de la microhistoria de la publicidad moderna a través del estudio de los orígenes de la práctica profesional de la Dirección y Gestión de Cuentas.

\section{En busca de las raíces de la Dirección y Gestión de Cuentas: del agente de publicidad a la agencia de publicidad moderna.}

I propose that we get our students into the early literature, give them a developmental framework, and then teach them to look for ideas and not labels or terms. (Wrend, 1977: 13)

La aparición de las modernas agencias de publicidad no se produjo de forma espontánea. Fue el resultado de un proceso evolutivo que tuvo su arranque en la 
figura del agente de publicidad y, antes de éste, incluso, en el llamado, genéricamente, agente. La búsqueda de los fundamentos de la Dirección y Gestión de Cuentas nos remonta a ese agente ya que su actividad profesional reúne algunas de las funciones que, posteriormente, y convenientemente adaptadas, formarán parte de la job description del moderno profesional de cuentas. El agente (publicitario) opera con claridad a mediados del siglo XIX y su trabajo se muestra vinculado a la actividad publicitaria y periodística. Su trabajo era, originalmente, desde una perspectiva profesional formal, un tanto desestructurada y, a menudo, tenía un carácter complementario (algunos agentes lo ejercían al margen de otra actividad profesional principal). Sin embargo, en la medida que estos agentes vieron crecer las oportunidades de negocio que les ofrecía actuar como figura mediadora, entre los anunciantes y la prensa, ocupándose de la contratación de espacios y de la inserción de los anuncios, fueron especializándose y adquiriendo un cierto reconocimiento profesional. A mediados del siglo XIX, en Estados Unidos, el número de agentes que gestionaban los anuncios para los periódicos había proliferado y sus actividades se habían ampliado. Estos agentes conocían los medios de la época y habían desarrollado habilidades como gestores, consejeros y negociadoras con la prensa y los anunciantes. Sin embargo, su remuneración procedía exclusivamente de los periódicos, de quienes recibían una comisión económica por su trabajo de captación de anunciantes y gestión de anuncios. Muchos de estos agentes operaban desde sus despachos o primeras agencias de anuncios o, si se prefiere, primeros despachos de publicidad, actuando en un terreno intermedio entre los newspaper agents y los advertising agents. Para Hower, estos primeros negocios, agencias o despachos, merecen todavía la consideración de agencias de los periódicos o newspaper agencies. (Hower, 1949:13). La competencia entre estos agentes creció y el valor de su trabajo residía en su capacidad para facilitar el trabajo a los anunciantes y, especialmente, para obtener precios más bajos de los diarios. Con este propósito, los agentes llegaban a utilizar parte de la comisión que recibían de los periódicos como descuento personal a sus clientes. A medida que se ponía en juego su margen económico y, por lo tanto, sus beneficios, el agente empezó a sentirse más autónomo del medio y a actuar de una forma más independiente de éste, priorizando sus propios intereses. Hacia 1860, en Nueva York, operaban más de veinte agencias de anuncios, al parecer sin una protección estatutaria, y ocupándose también de hacer las estimaciones de circulación y distribución de los periódicos. (Schuwer, 1966: 66). En esos años, algunos de estos agentes aportaron innovaciones importantes a su labor de intermediación, por ejemplo, invirtiendo en la compra de un volumen importante de espacios publicitarios a la prensa para venderlo luego en pequeñas unidades a los anunciantes y obtener un beneficio económico en esta operación. Estos agentes actuaron como una especie de mayoristas de espacios, o space-wholesaling (Hower, 1949:15). Otros alcanzaron acuerdos de negociación con la prensa a medio y largo plazo de manera que se convirtieron en exclusivistas, parciales o totales, de los espacios publicitarios de algunos periódicos. Este tipo de iniciativas dio pie a que las relaciones entre los agentes, o primeras agencias, y sus clientes fueran más regulares. En la década de 1870, algunas de estas agencias, o despachos, ya mostraban una estructura organizativa en la que intervenían distintos 
tipos de profesionales. Las funciones administrativas, contables, de gestión y supervisión del proceso de contratación de espacios, así como de comprobación de la publicación de los anuncios y de registro y archivo de los mismos, ya estaban estructuradas. Sin embargo, las agencias todavía no habían incorporado a los redactores publicitarios, directores de arte o diseñadores, especialistas en investigación, ejecutivos de cuentas, ni a otros perfiles que reconocemos en la agencia de publicidad moderna. $\mathrm{O}$ al menos, no lo habían hecho formalmente a pesar de que, en ocasiones facilitaban la redacción de los anuncios. A finales de la década de 1870 se produjo un hecho importante para la evolución de la actividad de estos agentes y agencias. En torno a 1875-1876, la agencia de publicidad NW Ayer \& Son (fundada en 1869) se planteó instaurar una nueva fórmula para remunerar sus servicios de manera que también fueran los anunciantes -y no sólo los medios, a través de comisiones o descuentos- quienes pagasen por el trabajo realizado por la agencia. El nuevo sistema contemplaba la firma de un contrato, llamado open contract, con el que el anunciante mostraba su acuerdo en pagar una comisión a la agencia, aplicada sobre la base del montante de su inversión publicitaria, como contraprestación a sus servicios. (Hower, 1949: 58). A principios del siglo XX, diversas agencias habían adoptado este sistema de remuneración aunque otras mantuvieron otras modalidades. Este cambio en la concepción de la fuente de negocio de las agencias llevaba implícito un cambio en la concepción del propio negocio publicitario y ello repercutió en gran manera en su forma de trabajar y, en particular, en el modo de concebir la relación con los anunciantes. Las agencias, aunque no renunciaron a su actividad y a una estrecha relación con los medios, reorientaron sus actuaciones con el objeto de atender prioritariamente a las diversas necesidades de los anunciantes en relación a la publicidad. Esto representó un cambio de paradigma trascendental. Así, ampliaron sus servicios tratando de darles un mayor valor y utilidad y vieron en ello un potencial importante para la expansión de su negocio. A finales del siglo XIX, muchos de estos modernos agentes de publicidad -algunos de ellos fundadores de las primeras agencias de publicidad- eran, además de unos buenos conocedores de los medios y gestores de la publicidad, conocedores y consejeros de la actividad comercial de sus clientes. Existen numerosos testimonios de la evolución profesional experimentada. A modo de ejemplo, Cherington recoge la intervención de Freeman, de la agencia de publicidad de Chicago Nichols-Finn Advertising Company, en la reunión de la National Association of Advertising Agents (1873). En ella, Freeman observa que, para numerosas agencias, el consejo, gestión y compra de espacios en la prensa empezaba a dejar de ser su actividad principal y se hacía eco de la emergencia de un nuevo perfil profesional con más atribuciones que el agente tradicional que venía actuando de forma independiente o bien integrado en la estructura de una agencia. (Cherington, 1913: 500). El perfil de este nuevo agente es notablemente distinto al de sus antecesores: "These man are business men before they are advertising men. They are business counselors and business advisers, with an organization back of them, to carry out in detail what they recommend in conference. (...) These men are students of commerce, of economics, of distribution, of trade conditions; they are alive to financial conditions in practically all divisions of business. They know about exports, imports; they 
have studied commercial law and together they represent a fund of business information such as no one man could give and such as no business man could hire outside of an institution of this character". (Cherington, 1913: 500). Este agente de publicidad moderno ya muestra algunas características y diversas funciones que, en buena parte, heredarán los modernos profesionales de cuentas. Entre 1870 y 1910, las agencias de publicidad han ampliado sus servicios y en sus discursos destacan su capacidad para ofrecer una atención personalizada así como la posibilidad de elaborar los anuncios, idear campañas de publicidad $\mathrm{y}$, en general, responder a una actuación planificada que, de una forma más o menos velada, enuncia la existencia de un pensamiento estratégico que se materializa en la formulación de un plan de publicidad. Como muestra de ello, en 1904, J. Walter Thompson explicaba a los anunciantes las ventajas de trabajar con una agencia que ofrecía un trato personalizado a través de un profesional experto en el manejo y la dirección general de la campaña de publicidad.

Moreover every contract we take gets the personal attention of a responsible man, experienced in the handling of appropriations and the general direction of advertising campaign. He will be almost as much your representative as if we were actually in your employ. He will become for the time being and additional and value part of your business machinery, while remaining a part of our and participating in its constants impetus. (J. Walter Thompson Company, 1904:9).

Efectivamente, el trato personal que ofrecía J. W. Thompson venía canalizado por un profesional responsable, con experiencia en tratar los asuntos y presupuestos de los anunciantes y capaz de conducir la dirección general de la campaña de publicidad. Este profesional, y primer interlocutor del anunciante, representaba los intereses de éste de un modo similar a cómo lo haría si estuviera integrado en su plantilla de empleados; su implicación en los intereses del anunciante era tal que debía identificarse con él y convertirse en una pieza más del engranaje de su negocio, aunque su pertenencia y formación seguiría proviniendo de la agencia y del trabajo que desarrollaba junto a otros profesionales que intervenían en las diferentes fases del proceso productivo y que se agrupaban en distintos departamentos especializados. En este periodo, la estructura organizativa de las agencias era ya más compleja, independientemente de que mostrasen métodos o estilos de trabajo propios. En la figura que apunta J. Walter Thompson puede identificarse con claridad el perfil del moderno profesional de cuentas (Solanas, 2011: 338). La complejidad del negocio publicitario había crecido, habían aumentado en número y variedad los servicios ofertados y también el número de clientes y el volumen de inversión publicitaria que manejaban. Todo ello requería una involucración mayor y más continuada para con el anunciante. En 1896, algunos empleados de NW-Ayer \& Son formulaban su petición de contar con un ejecutivo que se ocupase de la supervisión y coordinación del trabajo interno de la agencia, de manera que la dirección o conducción del trabajo del día a día se separase de la función directiva (Hower, 1949:475). El personalismo del agente de publicidad había sido relevado por la actuación de unas organizaciones empresariales, las modernas agencias, que actuaban como expertas en servicios profesionales publicitarios y de asesoramiento comercial, compuestas por un conjunto de profesionales cuyas funciones se complementaban para satisfacer las diversas expectativas 
de los anunciantes. Charles Austin Bates afirmaba que el 25\% del trabajo de agencias modernas como la suya equivalía al realizado por los agentes pero subrayaba que la diferencia residía en el $75 \%$ restante de su actividad y en su capacidad para elaborar y orquestar un plan de publicidad. (Bates, 1905: s.p). También la agencia McJunkin Advertising argumentaba que la eficacia de la publicidad se sostenía por un plan de comercialización sólido que contemplase la importancia del producto, el esfuerzo conjunto de la compañía, del canal de distribución y de venta. (Mc Junkin; Finn, 191x: 5). La incertidumbre que podía sentir el anunciante en décadas anteriores respecto a la publicidad se había reducido notablemente.

\section{La especialización y la integración de los servicios en la agencia de publicidad moderna.}

La ampliación de los servicios ofrecidos y la vocación de atención al anunciante supusieron el gran empuje para la aparición del profesional de cuentas. Las agencias habían incorporado formalmente los servicios de redacción y diseño publicitarios $\mathrm{y}$, muchas de ellas, también el servicio de investigación, sumándose a los ya existentes en torno a la actividad con los medios y al dominio de los procesos técnicos de pre-producción y producción publicitarios. Las necesidades de canalizar internamente la información, de hacer un seguimiento y coordinación continuados de los procesos de trabajo y, especialmente, de integrar las visiones y trabajos de los distintos especialistas de la agencia que intervenían en esos procesos, crecieron notablemente. Del mismo modo, también aumentó la necesidad de mantener una relación fluida y continuada con los anunciantes y de demostrarles que las propuestas de la agencias respondían a sus intereses comerciales, pudiendo obtener resultados palpables, en términos de eficacia, de su inversión publicitaria. En este sentido, la incorporación formal de la investigación (de mercado y publicitaria en general) constituyó una palanca de empuje fundamental para la concreción de la figura profesional de cuentas. La investigación fue una valiosa fuente de información para alimentar y dar solidez a las recomendaciones de las agencias. La figura del profesional de cuentas, que venía actuando de una manera más o menos velada, o permanecía aún indefinida, adquirió un mayor protagonismo desbordando su carácter o función tradicional eminentemente comercial. Era necesario mantener, o recuperar, una figura que tuviese una visión generalista, amplia y de conjunto de los procesos de trabajo y que tomara las riendas de su puesta en marcha, su ejecución y su seguimiento. De este modo, la visión operativa e instrumentalista de la publicidad, característica de otras épocas, quedaba formalmente guiada por una visión estratégica, no sólo general de la publicidad, sino diseñada, o adaptada, a la medida de cada anunciante y a las necesidades particulares de sus marcas. Este proceso cuajó en una revisión final de las funciones de carácter directivo que venían ejerciendo de forma directa y personal los propios fundadores de las agencias o sus más altos directivos. Profesionales con diferentes perfiles directivos y de agencia, como Albert D. Lasker (Lord \& Thomas), 
Henry Nelson McKinney (NW Ayer \& Son), o Stanley B. Resor (J. Walter Thompson), son buenos ejemplos de altos directivos de agencias punteras de la época que aglutinaban responsabilidades que, en parte, serán delegadas -o compartidas- en el futuro, en aquellos que identificamos como directores de cuentas, de servicios al cliente, de nuevo negocio e, incluso, posteriormente, algunos planificadores de cuentas. Estos altos directivos se habían visto forzados a multiplicar sus dedicaciones ante las dimensiones y complejidad que había adquirido el negocio publicitario. Las ideas de organización empresarial eficiente y equipos de trabajo se fueron imponiendo en las agencias, sin que ello ensombreciera el papel de liderazgo que siguieron manteniendo muchos de sus dirigentes. De este modo, el nuevo perfil profesional de cuentas recogió una parte de su herencia y fue una forma de personalizar la prestación de un servicio publicitario global por parte de la agencia y a la vez darle una fisonomía concreta. Este profesional actuará como una especie de columna vertebral organizativa: dará sostén a los diferentes sistemas internos de trabajo, consecuencia de la especialización por áreas, y será, directa o indirectamente, activador y conductor de procesos y equipos de trabajo. Con ello se formalizó un proceso de descentralización de la función directiva en relación con los proyectos de los clientes, o cuentas, de la agencia. Este cambio supuso también la extensión de un nuevo método de trabajo entre las agencias, una nueva sistematización operativa general en la que los parámetros organizativos y ejecutivos ganaron protagonismo. (Solanas, 2011: 457-463). En las décadas de 1910 y 1920, los servicios de las agencias ya aparecen estructurados en torno a las cuatro áreas características del modelo de agencia de servicios plenos o generales, o full service agency: la dirección y gestión de cuentas, la investigación, el servicio de medios y el servicio creativo.

\section{El reconocimiento de la función Ejecutiva en la full service agency.}

A finales de la década de 1910 y a principios de la de 1920, se constata la importancia de la labor ejecutiva desempeñada por unos profesionales de cuentas que lideran la relación con los anunciantes y cuyo trabajo aparece directamente vinculado a la formulación de una estrategia y de una actuación planificada. La investigación bibliográfica, y de una forma particularmente trascendente el testimonio de Roland Hall, muestra su posición privilegiada en el organigrama de algunas agencias; en ellas, aparece un staff ejecutivo, que ocupa una posición dominante, en el que participan el director of account, los executive officers y el manager of account. (Hall, 1921: 66, 70 y 71). A pesar de que Hall no incluye una descripción de sus responsabilidades ni detalla su modo de proceder, el análisis de las tres representaciones graficas que presenta este autor permite deducir algunas cuestiones relevantes. Los miembros de este staff ejecutivo son los responsables de canalizar el consejo profesional y las actuaciones de la agencia en el ámbito del marketing y de la comunicación publicitaria. Aparecen vinculados a la dirección de la agencia y al manejo del negocio en calidad de directivos intermedios o de segundo rango. Su trabajo está directamente 
relacionado con la formulación de planes y la toma de decisiones. Los executive officers eran, muy probablemente, los principales interlocutores de los anunciantes y los principales responsables de conducir las reuniones con éstos y su responsabilidad se asemeja a la de un moderno director de servicio al cliente -client services director. En este sentido, serían los primeros depositarios de algunas de las funciones que antaño se concentraban en los directores de las agencias o máximos responsables de éstas. El staff ejecutivo se ocupaba de llevar a cabo las labores de recopilación, búsqueda y análisis de la información (de producto, mercado, competencia, distribución y ventas, etc.) imprescindibles para ofrecer un consejo de carácter estratégico de marketing y publicidad. Para ello contaban con el apoyo del departamento de investigación que Hall ejemplifica a través del Research and Information Service de la agencia Tracy-Parry Company. (Hall, 1921: 71). En estos años, como se ha tratado de mostrar, las agencias resaltan su capacidad para saber interpretar y manejar la información de carácter marketiniano en torno a los productos y servicios, su capacidad de definir el público adecuado o target de la comunicación publicitaria y de encontrar el modo de presentar de forma convincente las ventajas del producto a éste, y ahora el staff ejecutivo se presenta como el responsable directo de ejercer y/o aglutinar estas funciones. Este equipo ejecutivo asumía la labor de concretar el mensaje que debía comunicarse, el modo cómo debía hacerse y de definir el público al que preferentemente debía dirigirse la comunicación. El conjunto de este trabajo se materializaba en la formulación de un plan -de campaña o plan de acción- que era presentado al anunciante por los miembros del staff ejecutivo. En estos años las agencias resaltaban en sus discurso su capacidad para saber interpretar y manejar la información de carácter marketiniano en torno a los productos o servicios, su capacidad de definir el público adecuado y de encontrar el modo de presentar de forma convincente las ventajas del producto a éste. El staff ejecutivo era el responsable directo de ello. Concretaba el mensaje que debía comunicarse, el modo cómo debía hacerse y definía el público al que preferentemente debía dirigirse la campaña.

\section{Conclusiones}

La síntesis evolutiva presentada permite afirmar que la definición, formalización y reconocimiento de la función ejecutiva, como especialización profesional en las agencias de publicidad, supuso el cierre de una etapa en la que tuvo lugar el proceso de modernización y de construcción del modelo de agencia paradigmático, la full service agency. Esta función ejecutiva tomó forma profesional en la Dirección y Gestión de Cuentas, que recogió un rol directivo, conductor y estratégico del servicio ofertado por la moderna agencia de publicidad a la vez que mantuvo sus atribuciones de carácter gestor, operativo y administrativo. A juicio de la autora, el conocimiento de los fundamentos que originaron la Dirección y Gestión de Cuentas permite una valoración y justo reconocimiento de la trascendencia de su contribución profesional -a menudo olvidada- en la construcción del sistema y de la industria publicitaria 
moderna. Por último, el conocimiento de sus raíces muestra su identidad original y aporta claridad al debate sobre su ejercicio actual, especialmente en las vertientes estratégica y directiva.

\section{Bibliografía}

BATES, CH.A. Good advertising and where it is made. New York: Charles Austin Bates, 1905.

CHERINGTON, P.T. (1913): Advertising As A Business Force. [S.1]: Doubleday, Page \& Company.

HOWER, R. (1949): The history of an advertising agency. N.W. Ayer\& Son at Work. 1869-1949. Cambridge: Harvard University Press, 1949.

McJUNKIN, W.D.; FINN, J.H. (191x). Master Merchandising and The Dominant Idea. [S.1]: Mc-Junkin Advertising Company.

SCHUWER, P. (1966). History of advertising. London: Leisure Arts, 1966.

SOLANAS, I. (2011). Orígenes de la publicidad moderna (1800-1925). La aparición de la dirección y gestión de cuentas como función profesional en las agencias de publicidad modernas. Saarbrücken, Alemania: editorial académica española.

WREND, Daniel A. (1977): "Management Terminology: A Historical Perspective". Academy of Management Proceedings.

\section{La autora}

Isabel Solanas García. Doctora en Publicidad por la Universidad Ramón Llull (2011) y licenciada en Publicidad y Relaciones Públicas por la Universidad Autónoma de Barcelona (1985).

Co-autora del libro Dirección de Cuentas. Gestión y planificación de cuentas en publicidad (Barcelona, UOC, 2008). Ha escrito diversos artículos académicos y también de carácter divulgativo en la prensa general y sectorial publicitaria. Desde 1998 se ha dedicado plenamente a la docencia universitaria.

Con anterioridad desarrolló su trayectoria profesional en el área de cuentas en agencias de publicidad como J. Walter Thompson (JWT) y Darcy, Masius, Benton \& Bowles (DMB\&B). 